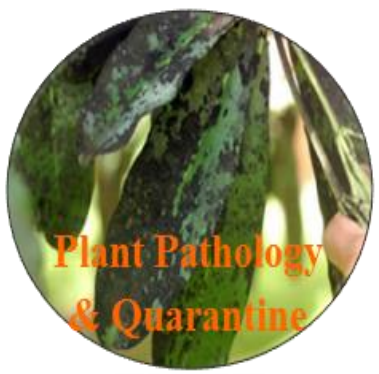

Plant Pathology \& Quarantine 7(2): 92-94 (2017)

ISSN 2229-2217

\title{
X-ray imaging for detecting lack mould rot of sapota (Achras sapota) fruit
}

\section{Gadgile D*, Lande BR, Dhabde AS and Kamble SP}

Department of Botany, Madhavrao Patil Arts, Commerce \& Science College, Palam Tq- Palam Dist. Parbhani (M.S.), India

Gadgile D, Lande BR, Dhabde AS, Kamble SP 2017 - X-ray imaging for detecting black mould rot of sapota (Achras sapota) fruit. Plant Pathology \& Quarantine 7(2), 92-94, Doi 10.5943/ppq/7/2/1

\begin{abstract}
The detection of black mould rot infection (Aspergillus niger) in post-harvest sapota fruit was demonstrated by a X-ray imaging technique carried out six, seven and eight days post inoculation. It is suggested that X-ray imaging technology for detection of fungal infection may be useful as an imaging-based sapota sorting system.
\end{abstract}

Key words - Aspergillus niger - post-harvest disease - sapota - X-ray scanning

\section{Introduction}

Black mould rot, caused by Aspergillus niger is an important disease of sapota (Achras sapota) fruit. Thomas et al. (1993), Yang et al. (2006), Janave (2007) and Gadgile \& Chavan (2017) reported that X-ray can be applied to detect plant diseases. There are no reports of use of X-ray imaging to detect fungal infection in post-harvest fruits of sapota. The objective of the present study was to detect black mould rot infection of sapota fruit by X-ray imaging.

\section{Materials \& Methods}

\section{Isolation of fungi}

Black mould rot diseased fruits of sapota were collected from a fruit market of Palam Dist., Parbhani (M.S.) and taken to laboratory of Department of Botany, Madhavrao Patil Arts, Commerce and Science College, Palam Dist., Parbhani (M.S.), India. The pieces of infected fruits were surface sterilized with $2 \%$ sodium hypochlorite and immediately rinsed with tap water. A. niger was isolated on agar plates and colonies were purified using single spore technique.

\section{X-ray scanning of fruits}

X-ray scanning of sapota fruits was carried out by using method of Gadgile \& Chavan (2017). Spore suspensions of A. niger were prepared and inoculated in to same sized healthy sapota fruits using sterilized disposable syringes in aseptic conditions. Healthy sapota without inoculation was treated as control. Six, seven and eight days following inoculation, these fruits were scanned by a digital X-ray 
system. The specifications with which X-ray exposure was taken were $\mathrm{kv}=63, \mathrm{~mA}=160$ and $\mathrm{mAs}=$ 13.

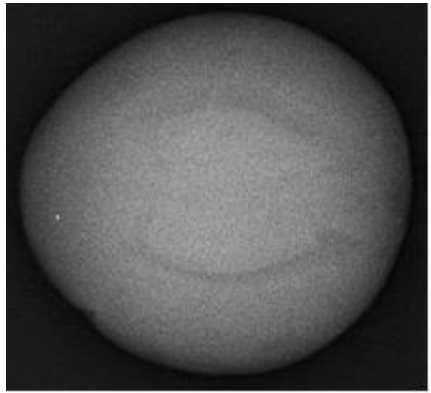

A

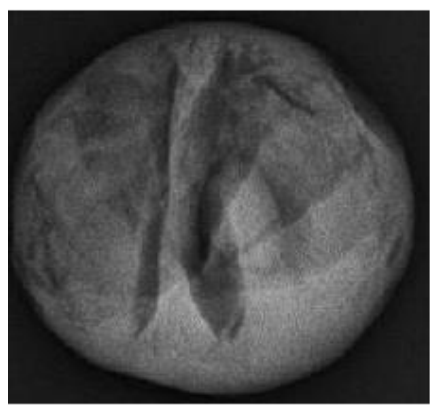

D

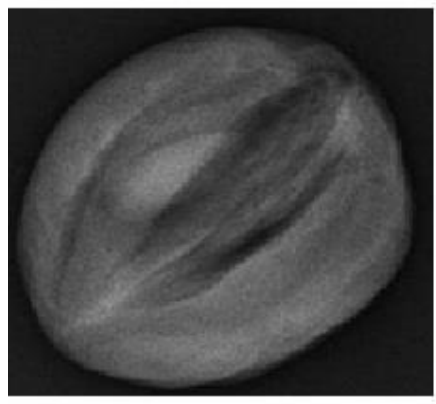

G

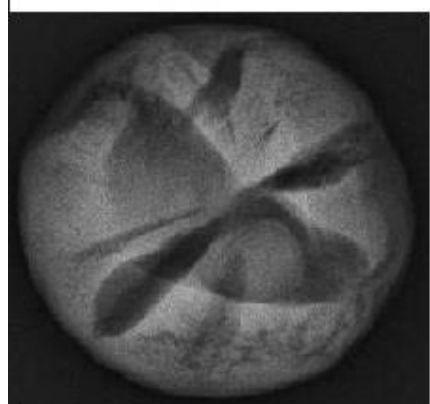

J

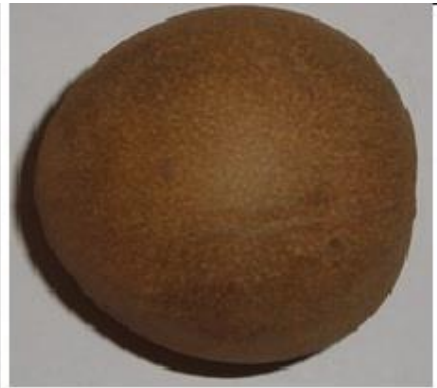

B

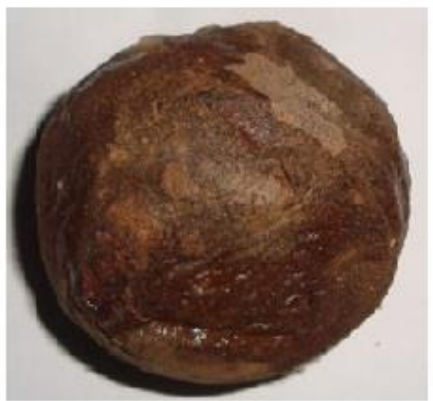

E

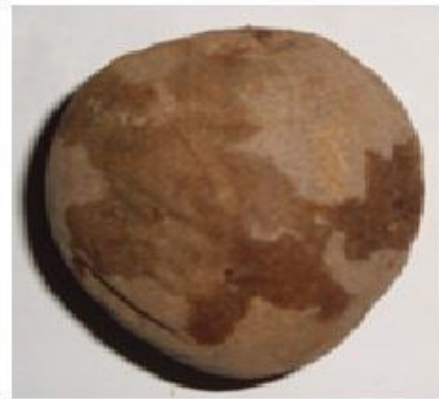

H

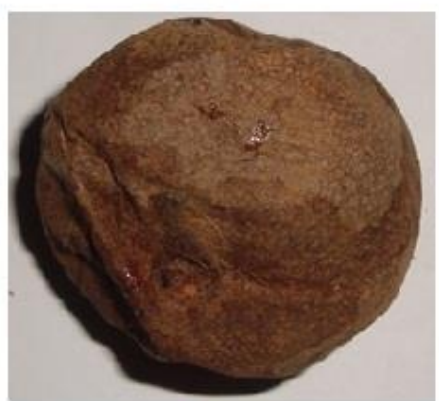

K

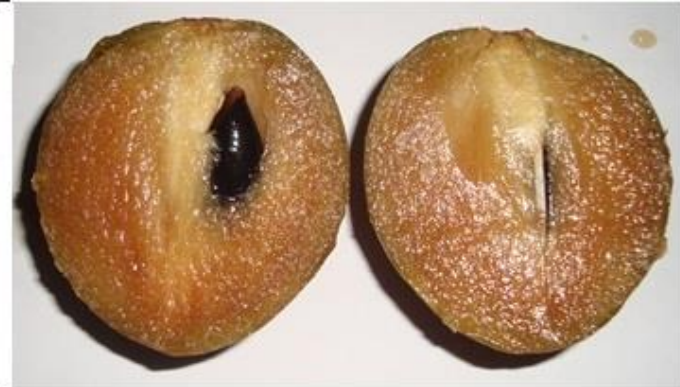

C

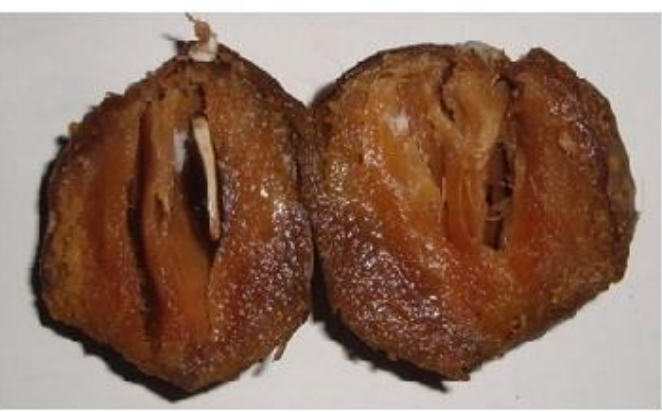

F

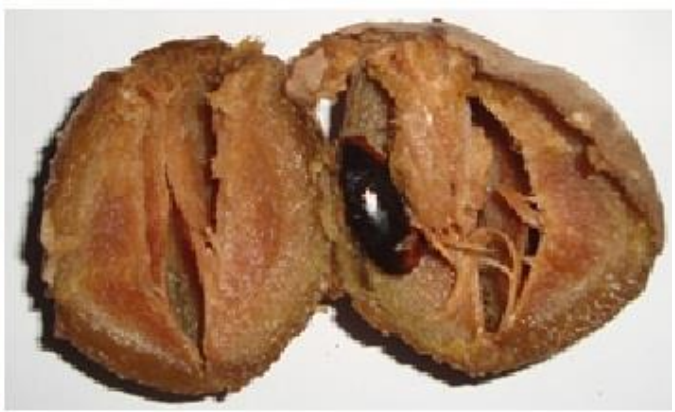

I

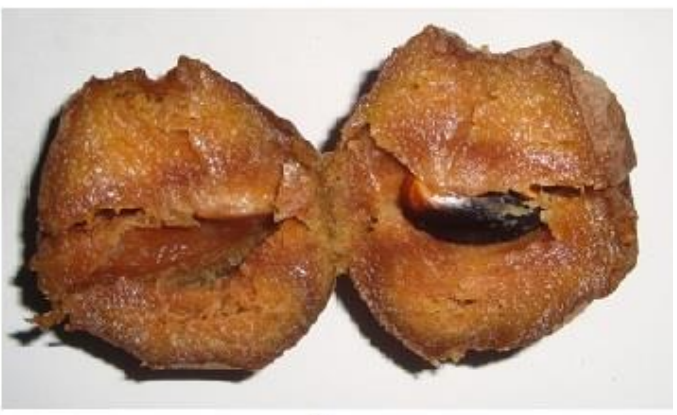

L

Fig. 1 - X-ray scanning of black mould rot of sapota fruit. A. X-ray image of healthy fruit. B. Healthy uncut fruit. C. Healthy cut fruit. D. X-ray image of fruit 8 days post-inoculation. E. uncut fruit 8 days post- inoculation. F. cut fruit 8 days post-inoculation. G. X-ray image of fruit 7 days post-inoculation. H. uncut fruit 7 days post-inoculation. I. cut fruit 7 days post-inoculation. J. X-ray image of fruit 6 days post-inoculation. K. uncut fruit 6 days post-inoculation. L. cut fruit 6 days post-inoculation. 


\section{Results}

Six, seven and eight days after inoculation, infection of sapota fruit could be detected by X-ray scanning (Fig. 1). X-ray scanning of infected fruit showed dark areas in fungal infected portion while uninfected fruit showed a uniform light grey area. After X-ray imaging when infested fruits were cut, infection was seen clearly.

\section{Discussion}

To the best of our knowledge, this is the first report on application of X-ray to detect fungal infection of sapota fruit. Gadgile \& Chavan (2017) reported similar results in mango fruits. Results of present study may be applied in the X-ray imaging-based sapota sorting system which may be useful for traders exporting bulk quantities of fruits.

\section{Acknowledgements}

Thanks are due to Principal, Madhavrao Patil Arts, Commerce \& Science College, Palam (M.S.) India for providing necessary facilities. Authors also thank Dr. Manish Biyani, Biyani Hospital, Gangakhed Dist Parbhani (M.S.), India for providing free of cost X-ray scanning facilities.

\section{References}

Gadgile D, Chavan A. 2017 - Detection of post-harvest fungal diseases of mango by X-ray scanning non-destructive technology. Plant Pathology \& Quarantine 7(1), 65-69.

Janave MT. 2007 - Biochemical changes induced due to staphylococcal infection in spongy Alphonso mango (Mangifera indica L.) fruits. Journal of Crop Science and Biotechnology 10, 167-174.

Thomas P, Saxena S, Chandra R, Rao R, Bhatia CP. 1993 - X-Ray imaging for detecting spongy tissue, an internal disorder in fruits of Alphonso mango (Mangifera indica L.). Journal of Horticulture Science 68, 803-806.

Yang EC, Yang MM, Liao LH, Wu WY, Chen TW, Chen TM, Lin TT, Jiang JA. 2006 - Nondestructive quarantine technique - potential application of using X-ray images to detect early infestations caused by Oriental fruit fly (Bactrocera dorsalis) (Diptera: Tephritidae) in fruit. Formosan Entomologist 26, 171-186. 